\title{
MODIFIED ENDOVENTRICULAR CIRCULAR PLASTY (DOR PROCEDURE) IN A PATIENT PRESENTING WITH ACUTE SHORT-TERM MEMORY LOSS
}

\author{
Olaniran Omodara ${ }^{1}$, Rahul Basu ${ }^{1}$, Adam Szafranek ${ }^{1}$, and Surendra Naik ${ }^{1}$ \\ ${ }^{1}$ Nottingham University Hospitals NHS Trust
}

May 6, 2020

\begin{abstract}
OVERVIEW A long-term complication of acute myocardial infarction (AMI) is an aneurysm of the left ventricle (LV) resulting mostly in cardiac failure, ventricular tachycardia (VT), and thromboembolic episodes. Post-infarction LV aneurysm results in LV dilatation and abnormal geometry leading to systolic and diastolic dysfunction. Sudden cardiac death often results from VT after AMI. Conventional surgeries like coronary artery bypass alone have been shown to have minimal benefits in patients with cardiac failure. In a prospective 10-year follow-up study on survival after myocardial revascularization for ischaemic cardiomyopathy, Shah et al reported that coronary artery bypass grafting (CABG) alone after ischaemic heart disease and low left ventricular fraction results in relief of angina symptoms. This particular case was quite interesting because of its unusual presentation and also the progression of symptoms with the attendant deterioration of LV function.
\end{abstract}

MODIFIED ENDOVENTRICULAR CIRCULAR PLASTY (DOR PROCEDURE) IN A PATIENT PRESENTING WITH ACUTE SHORT-TERM MEMORY LOSS

Olaniran Omodara MWACS, Rahul Basu FRCA, Adam Szafranek FRCS, Surendra Naik FRCS

\section{Correspondence}

Olaniran Omodara, Department of Cardiac Surgery, Nottingham University Hospital NHS Trust, Nottingham, United Kingdom

Email- olaniranomodara2002@yahoo.com

Running head- Dor Procedure Nottingham

Keywords- Cardiovascular research, coronary artery bypass grafting

A 64 year old male patient was admitted to hospital with acute onset short-term memory loss associated with abnormal behaviour and a left sided headache. Collateral history from his family reported he had a two week history of chest tightness and discomfort. He had been reviewed in primary care who felt his symptoms were due to reflux. He denied any history of head injury or other neurological symptoms. His past medical history included gastro-esophageal reflux disease and mild Factor VII deficiency.

Initial assessment in Accident and Emergency showed no neurological deficit on examination. There was prior history of shortness of breath on exertion. He was fully oriented to time and place; however, he was unable to recall events leading up to admission. He was tachycardic, other observations and physical examination were normal.

The 12 lead electrocardiogram (ECG) showed normal sinus rhythm with ST elevation in leads V3-V6, I, II and aVF. Serial troponins done on day 1 and day 2 of admission were 152ng/L and 334ng/L respectively. 
Computerised Tomography (CT) scan of the brain was normal.

Magnetic Resonance Imaging (MRI) of the brain confirmed an acute left parietal lacunar infarct.

The patient was admitted to the cardiology ward and treated as a delayed presentation of an anterior ST elevation myocardial infarction (STEMI). Coronary angiography revealed complete occlusion of the mid left anterior descending (LAD) coronary artery (Figure 1) with minimal disease in the left circumflex and moderate to severe disease in his right posterior descending artery (Figure 2).

Trans-thoracic echocardiogram (TTE) showed an apical left ventricular aneurysm with and large thrombus measuring $4 \times 5 \mathrm{~cm}$ with a left ventricular ejection fraction of $<10 \%$, moderate mitral regurgitation (MR) and moderate to severe tricuspid regurgitation (TR) (Figure 3).

He was treated with dual-antiplatelet therapy, a high dose statin, Eplerenone, a beta-blocker, angiotensinconverting enzyme inhibitor (ACE-I) and an anti-anginal medication.

He was managed by the Stroke team as it was thought that his cerebral infarction was caused by embolism from the left ventricular thrombus. He was initiated on Warfarin therapy and subsequently discharged from the hospital.

Echocardiogram six weeks post discharge showed further extensive akinesia of the left ventricle. Two months post discharge from hospital, cardiac Magnetic Resonance Imaging (MRI) was performed which showed a decrease in the left ventricular ejection fraction to $8 \%$ with full thickness infartion with no myocardial viability in six segments of the mid anterior, inferior and septal walls. There was severe left ventricular dilatation with thinning and akinesia of the left ventricular apex. However, there was improvement in the MR and TR as he now had mild MR and mild TR.

The patient was referred for an elective Dor procedure and was reviewed in the pre-operatively clinic. There was history of shortness of breath on exertion with NYHA III, mild angina CCS II and after reviewing investigations, he was counselled and he consented for the procedure.

\section{Operative steps}

He was anaesthetized in supine position with a single lumen endotracheal tube under general anaesthesia, invasive monitoring and urethral catheterization.

Transoesophageal echocardiogram revealed severe LV systolic dysfunction, mid-apical, infero-septal LV aneurysm with large LV thrombus.

Median sternotomy was performed with standard aortic cannulation and dual-stage single right atrial cannulation and cardio-pulmonary bypass established, cross clamp applied followed by warm induction antegrade followed by antegrade continuous cold blood cardioplegia and warm reperfusion antegrade before release of cross clamp with aortic root vent, right superior pulmonary venous vent. (Figure 4)

FINDINGS: LV clot, extensive aneurysm of the left ventricle, blocked LAD, extensive adhesions.

PROCEDURE: Aneurysm freed from the pericardium (Figure 5), opened vertically, clot removed (Figures $6,7)$. The area of transition between muscle and fibrous tissue was reasonably clear. Purse string was taken to reduce the size of the opening of the aneurysm and a Vaskutek patch, approximately $4 \mathrm{~cm} \mathrm{x} 3 \mathrm{~cm}$ was sutured with horizontal mattress sutures with pledgets on the LV side. The free margin of the patch was then continuously sutured to the wall of the aneurysm with 2-0 continuous prolene as a haemostatic layer (Figures 8, 9,10). The redundant aneurysm wall was excised and closed over the reconstruction. The patient came off bypass without any difficulty. The ejection fraction had significantly improved compared to the pre-op echo (Figure 11).

Total bypass time was 131 minutes, cross Clamp time was 112 minutes with effective/Ischaemic time of 0 minute. The patient was weaned off bypass with minimal support. 
Two right ventricular pacing wires and two right atrial pacing wires were used with AV sequential pacing because of slow sinus rhythm.

Post-operatively, he made an uneventful recovery and was discharged after 9 days.

Post-operative echocardiogram showed improved LVEF of 35\% (Figure 12).

He was reviewed in our post-operative out-patient clinic in 6 weeks and he has made a significant improvement, increased exercise tolerance with improved NYHA and repeat trans-thoracic echocardiogram revealed LVEF of $44 \%$ (Figure 13).

\section{OVERVIEW}

A long-term complication of acute myocardial infarction (AMI) is aneurysm of the left ventricle (LV) resulting mostly in cardiac failure, ventricular tachycardia (VT) and thromboembolic episodes. Post-infarction LV aneurysm results in LV dilatation and abnormal geometry leading to systolic and diastolic dysfunction. Sudden cardiac death often results from VT after AMI ${ }^{1}$. Aneurysm of the left ventricle mostly result from an acute occlusion of the left anterior descending artery (LAD) affecting the anterior wall and septum.

Conventional surgeries like coronary artery bypass alone has been shown to have minimal benefits in patients with cardiac failure ${ }^{2}$. In a prospective 10-year follow-up study on survival after myocardial revascularization for ischaemic cardiomyopathy, Shah et al reported that coronary artery bypass grafting (CABG) alone after ischaemic heart disease and low left ventricular fraction results in relief of angina symptoms, however prognosis on a long-term was very poor with $76 \%$ of the patients dying within 10 years mostly from cardiac failure $^{3}$. This has led to the evolution of several surgical modalities in managing diseased ventricles.

LV aneurysm repair was first performed in 1954 by Charles Bailey, Denton Cooley did the first resection with the use of cardiopulmonary bypass in 1958. Vincent Dor performed the first endoventricular circular patch plasty based on previous surgical procedures done by Cooley and Jatene ${ }^{4,5,6}$. Dor and his colleagues have subsequently reported excellent clinical and haemodynamic outcomes in many patients ${ }^{7}$. The Dor procedure excludes dyskinetic and akinetic parts of the septum and anterior wall, thus giving the LV a new shape anchored by a stitch that encircles the zone of transition between aneurysmal tissue and normal myocardium, and also using a patch to establish continuity of the ventricular wall. The procedure also allows for removal of clots, myocardial revascularization and mitral valve procedures when necessary ${ }^{4,8}$.

This particular case was quite interesting because of its unusual presentation and also the progression of symptoms with the attendant deterioration of LV function. It was a particularly challenging case in that there were extensive adhesions which made a bypass grafting impossible in this case. Even though it was very high risk surgery considering the $\mathrm{EF}$ was $<10 \%$ pre-op, there has a progressive improvement in EF, being $44 \%$ after 6 weeks post-operatively.

\section{REFERENCES}

1 Moss A J, Zareba W, Hall W J, Klein H, Wilber D J, Cannom D S, Daubert J P,

Higgins S L, Brown M W, Andrews M L. The Multicenter Automatic Defibrillator Implantation Trial II Investigators. Prophylactic implantation of a defibrillator in patients with myocardial infarction and reduced ejection fraction, $N$ Engl $J$ Med. 2002;12:877-883

2 Schinkel A F L, Poldermans D, Rizzello V, Vanoverschelde J-L J, Elhendy A, Boersma E, Roelandt J R, Bax J J. Why do patients with ischemic cardiomyopathy and a substantial amount of viable myocardium not always recover in function after revascularization?, J Thorac Cardiovasc Surg, 2004;2:385-390

3 Shah P J, Hare D L, Raman J S, Gordon I, Chan R K, Horowitz J D, Rosalion A, Buxton B F. Survival after myocardial revascularization for ischemic cardiomyopathy: A prospective ten-year follow-up study, $J$ Thorac Cardiovasc Surg, 2003;5:1320-1327 
4 Dor V, Saab M, Coste P, Kornaszewska M, Montiglio F. Left ventricular aneurysm: a new surgical approach, Thorac Cardiovasc Surg ,1989;1:11-19

5 Cooley DA. Ventricular endoaneurysmorrhaphy: a simplified repair for extensive postinfarction aneurysm, $J$ Card Surg, 1989;3:200-205

6 Jatene AD. Left ventricular aneurysmectomy. Resection or reconstruction, J Thorac Cardiovasc Surg, 1985;3:321-331

7 Dor V, Di Donato M, Sabatier M, Montiglio F, Civaia F. Left ventricular reconstruction by endoventricular circular patch plasty repair: a 17-year experience, Semin Thorac Cardiovasc Surg, 2001;4:435-447

8 Menicanti L, Di Donato M. The dor procedure: what has changed after fifteen years of clinical practice?, $J$ Thorac Cardiovasc Surg, 2002;5:886-890

\section{Hosted file}

Dor main picture.docx available at https://authorea.com/users/317973/articles/447995modified-endoventricular-circular-plasty-dor-procedure-in-a-patient-presenting-withacute-short-term-memory-loss 